\title{
Evaluation of Consumer ANd Producer Risk in CONFORMITY ASSESSMENT DECISIONS
}

\author{
Biserka Runje, Amalija Horvatić Novak, Andrej Razumić, Petar Piljek, \\ Branko Štrbac \& Marko Orošnjak
}
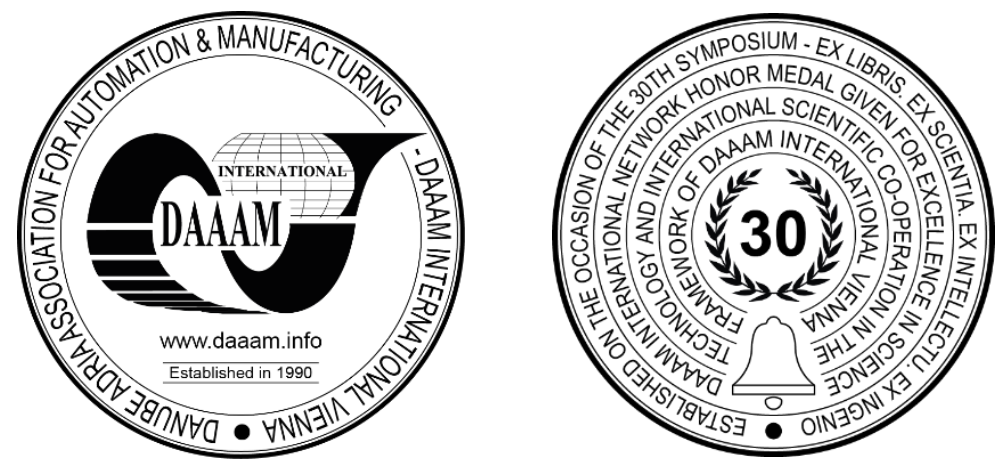

This Publication has to be referred as: Runje, B[iserka]; Horvatic Novak, A[malija]; Razumic, A[ndrej]; Piljek, P[etar]; Strbac, B[ranko] \& Orosnjak, M[arko] (2019). Evaluation of Consumer and Producer Risk in Conformity Assessment Decisions, Proceedings of the 30th DAAAM International Symposium, pp.0054-0058, B. Katalinic (Ed.), Published by DAAAM International, ISBN 978-3-902734-22-8, ISSN 1726-9679, Vienna, Austria DOI: $10.2507 / 30$ th.daaam.proceedings.007

\begin{abstract}
Conformity assessment is defined as any activity that is undertaken to determine whether a product, system or process meets the relevant standards and performs certain requirements. The decision whether the object of interest is in accordance with a request is based on the measurement results. The quality of the measurement results is described by the measurement uncertainty that is relevant to conformity assessment. The consumer and producer risks are described in this paper, as well as their impact on the conformity assessment and the way in which they can be managed. This paper also describes the impact of measurement uncertainty on the acceptance and rejection of a product according to its specifications.
\end{abstract}

Keywords: Consumer risk; Producer risk; Conformity assessment; Measurement uncertainty.

\section{Introduction}

Risk as an effect of uncertainty in the achievement of goals becomes a major factor in the planning and organization of business, and thus in quality management. Conformity assessment is the process used to demonstrate that a product meets specification limits. In conformity assessment decision making, the risk of a wrongly rejected product must be assessed, as well as the risk of the consumer using an accepted non-conforming product. Making a reliable decision in conformity assessment is only possible after calculating conformance probability, consumer risk (if the item has been accepted), producer risk (if the item has been rejected) and the acceptance intervals [1]. In order to ensure that producer and consumer risks do not exceed the permissible values, specification limits (the tolerance interval), the acceptance interval and standard uncertainty of the measurement result should be taken into account. Depending on the quality of the measurement results and the reliability of the risk assessment different decisions can be made, e.g. the decision to accept the product, to re-measure the product with a more accurate measuring system, to re-engineer the product, to reject the product, etc. [2]. The associated risk management methodology is developed in the reference document JCGM 106: 2012 [3]. and requires knowledge in the fields of probability and statistics as well as numerical integration, which makes it difficult for users to apply. 
In the paper, the binary decision rule was applied for calculating the conformity assessment using probability distributions. The influence of measurement uncertainty on consumer and producer risk was determined. The calculation was made based on the example of the production of a welding machine.

\section{Decision rules}

When defining the rules for the acceptance or rejection of an item, it is necessary to describe the document and the way in which the measurement uncertainty is taken into account with respect to the measurement result and specified requirements [4]. When the decision rule is based on simple acceptance (Figure 1.) the producer and user accept the measurement result within the tolerance interval and share the consequences of incorrect decisions. In that case, the measurement uncertainty has to be fit for purpose and acceptable to both sides.

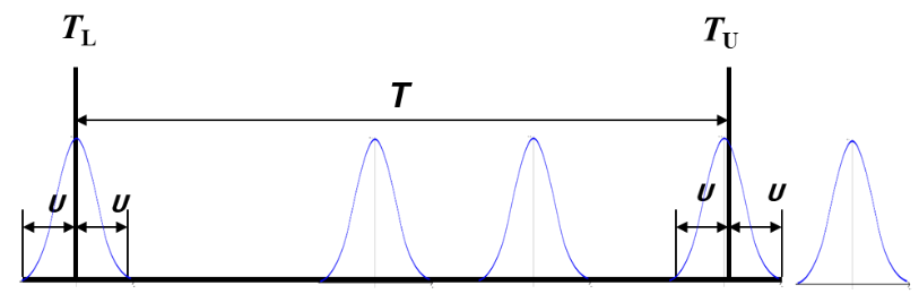

Fig. 1. Simple acceptance decision rule at lower and upper tolerance limits $T_{\mathrm{L}}$ and $T_{\mathrm{U}}[5]$

Where:

$T_{\mathrm{L}}-$ lower specification limit

$T_{\mathrm{U}}$ - upper specification limit

$T$ - tolerance interval

$U$ - expanded measurement uncertainty.

Relying on the simple acceptance decision rule and the measured value given by a normal distribution can lead to the probability of accepting a non-conforming item or rejecting a conforming item to be as high as $50 \%$ [3].

When conformity assessment is determined using a binary decision rule, a property of an item is measured, and the item is accepted as conforming if the measured value of the property lies within the defined acceptance interval (Figure 2).

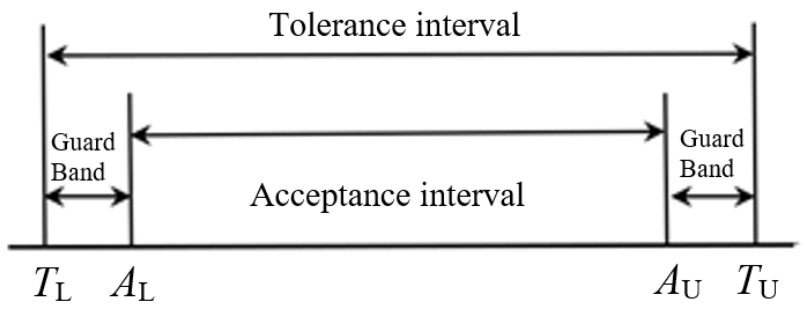

a)

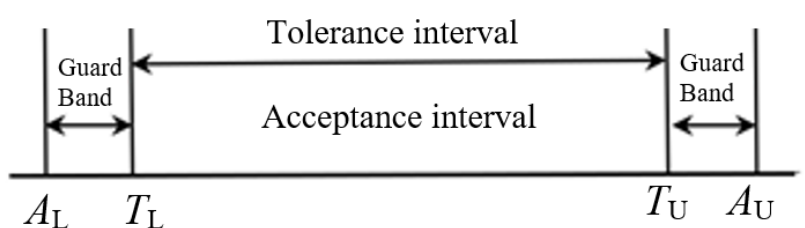

b)

Fig. 2. Binary conformity assessment:

a) in order to minimize consumer risk, b) in order to minimize the producer risk

Where:

$A_{\mathrm{L}}$ - lower acceptance limit

$A_{\mathrm{U}}$ - upper acceptance limit

The area between the tolerance limit and the acceptance limit is called a security area i.e. guard band and such a decision-making strategy is called guard banding. The use of the security area provides a way to limit the probability of making wrong decisions. An example of a binary conformity assessment for which decisions are based on value changes is provided in Figures 2a) and 2 b). The true value of the measured property is determined to lie in the tolerance interval, defined by the lower specification limit $\left(T_{\mathrm{L}}\right)$ and the upper specification limit $\left(T_{\mathrm{U}}\right)$. The result is accepted if it lies within the acceptance interval as defined by the lower acceptance limit $\left(A_{\mathrm{L}}\right)$ and upper acceptance limit $\left(A_{\mathrm{U}}\right)$. Figure $\left.2 \mathrm{a}\right)$ presents a binary conformity assessment, which was conducted in order to minimize the consumer risk (guard bands are within 
the tolerance zone). Figure $2 \mathrm{~b}$ ) presents a binary conformity assessment, conducted in order to minimize the producer risk (guard bands are outside the tolerance zone). In many cases, the guard band is defined as an expanded uncertainty $U$ with a coverage factor $k=2$ and an associated coverage probability of $P=95 \%$. The two-sided acceptance interval defined by the guard band with $U, k=2, P=95 \%$ was established as a decision rule for the first time in ISO 14253-1 [6] with the goal of minimizing consumer risk. Decision rules applied to a conformity assessment with two side tolerance limits are also valid for the purpose of conducting a conformity assessment with a single tolerance of a lower or an upper limit.

\section{Calculation of conformity assessment using a binary decision rule}

The binary decision rule has been applied for calculating the conformity assessment using probability distributions. The consumer $R_{\mathrm{C}}$ and producer $R_{\mathrm{P}}$ risks are calculated in accordance with JCGM 106:2012. In the paper, the calculation is made based on the example of the production of a welding machine.

A producer of welding systems and equipment produces a welding machine. The welding machine works in constant current mode, but during the welding process, the current oscillates, with the oscillation equaling several amps. The oscillations are not a good thing, and if they exceed a certain limit, the machine will stop working properly, and the weld will not be reliable. The nominal current for this kind of process is $200 \mathrm{~A}$. The machine works correctly if the current lies within the tolerance interval as defined by the tolerance limits with the lower specification limit $T_{\mathrm{L}}=196 \mathrm{~A}$ and upper specification limit $T_{\mathrm{U}}=204 \mathrm{~A}$. After conducting measurements for control purposes, the histogram of the obtained values looks like a normal distribution curve centered on the nominal value $y_{0}=200$ A with a standard deviation of $\sigma=u_{0}=2.7$ A. The probability of conformity $p_{\mathrm{c}}$ for the typical machine produced by the producer equals: $p_{\mathrm{c}}=0.8615 \approx 86 \%$.

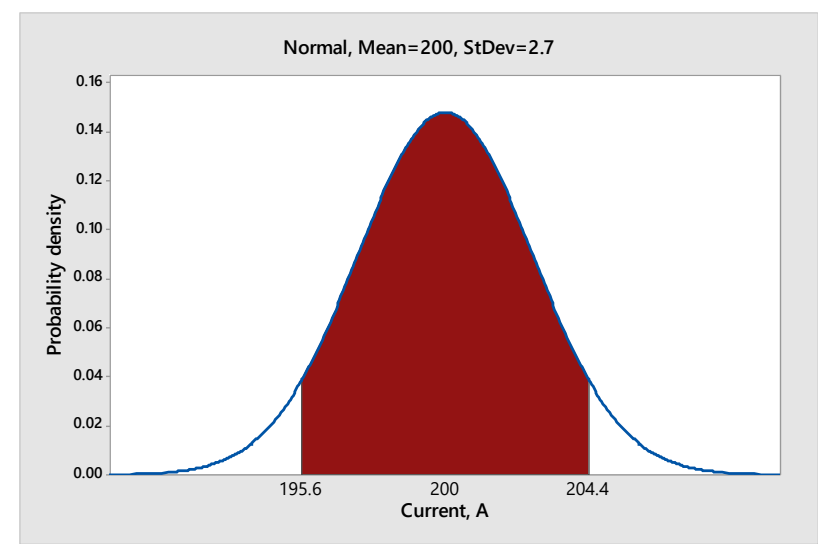

Fig. 3. The probability of conformity $p_{c}$

If the producer delivers every welding machine produced, approximately $14 \%$ of the machines delivered will be nonconforming. In this case, the probability of conformity is not at an acceptable level. While purchasing a more expensive machine can reduce machine variability the producer decided to keep the current welding machine and instead introduce a control process with the aim of excluding incompatible machines. In practice, the machines are controlled by a special set of equipment. The $u_{\mathrm{m}}=1.2 \mathrm{~A}$ is the value of the standard measurement uncertainty of the new equipment. With the aim of reducing the probability of delivering welding machines which do not satisfy the necessary requirements, the acceptance limits $\left(A_{\mathrm{L}}=196.6 \mathrm{~A}\right.$ and $\left.A_{\mathrm{U}}=203.4 \mathrm{~A}\right)$ are placed within specification limits at an equal safety area length distance on both sides. The safety area length $\omega$ is calculated as $\omega=204 \mathrm{~A}-203.4 \mathrm{~A}=0.6 \mathrm{~A}$. The consumer $R_{\mathrm{C}}$ and producer $R_{\mathrm{P}}$ risks are calculated in accordance with JCGM 106:2012 as following:

$$
\begin{aligned}
& R_{\mathrm{C}}=\int_{-\infty}^{\frac{T_{\mathrm{L}}-y_{0}}{u_{0}}} F(z) \varphi_{0}(z) \mathrm{d} z+\int_{\frac{T_{\mathrm{U}}-y_{0}}{u_{0}}}^{\infty} F(z) \varphi_{0}(z) \mathrm{d} z \\
& R_{\mathrm{P}}=\int_{\frac{T_{\mathrm{L}}-y_{0}}{u_{0}}}^{\frac{T_{\mathrm{U}}-y_{0}}{u_{0}}}(1-F(z)) \varphi_{0}(z) \mathrm{d} z
\end{aligned}
$$

Where:

$$
\varphi_{0}(z)=(1 / \sqrt{2 \pi}) \exp \left(-z^{2} / 2\right)
$$


$F(z)=\Phi\left(\frac{A_{\mathrm{U}}-y_{0}-u_{0} z}{u_{\mathrm{m}}}\right)-\Phi\left(\frac{A_{\mathrm{L}}-y_{0}-u_{0} z}{u_{\mathrm{m}}}\right)$

Consumer risk and producer risk were calculated by using numerical integration.

Consumer risk: $R_{\mathrm{C}}=0.0167=1.67 \%$.

Producer risk: $R_{\mathrm{P}}=0.1280=12.80 \%$.

Considering a sample of 100 produced welding machines, which are measured, accepted or rejected as suitable for use, in each case there exist some common fundamental features of such a process. Taking in to account the properties of the production process, $86 \%$ of the machines were found to be compatible with the consumer request and $14 \%$ machines are found to be incompatible with the request. From 86 compatible machines, 75 are accepted, and 11 of them are rejected as incompatible. From the 14 unsatisfactory machines, all of them are rejected as non-conforming. So, in the end, 75 machines are accepted and all of them are compatible. This is the goal of measurement control, to reduce the number of non-conforming machines accepted for use. In this example, the number of accepted non-conforming machines was reduced from $14 \%$ to $1.67 \%$. Of the 25 machines which were rejected, 11 of them (44\%) were rejected despite initially conforming to the request. This is a price that must be paid in order to reduce the risk of accepting non-conforming machines. The influence of measurement uncertainty on consumer and producer risk is presented in Figures $4 \mathrm{a})$ and $4 \mathrm{~b}$ ).

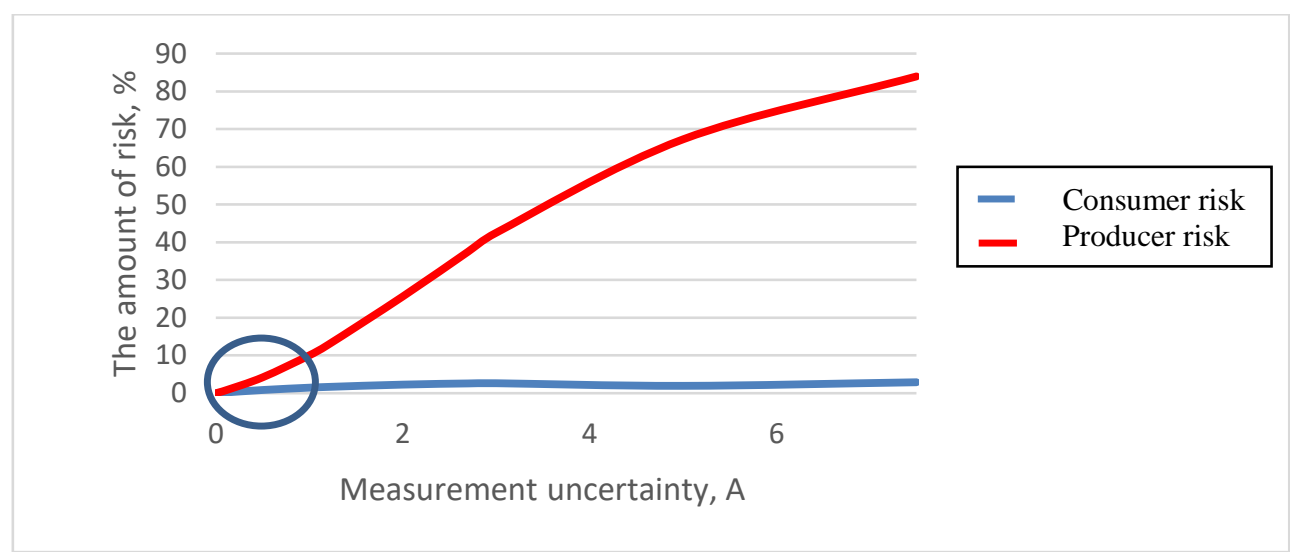

a)

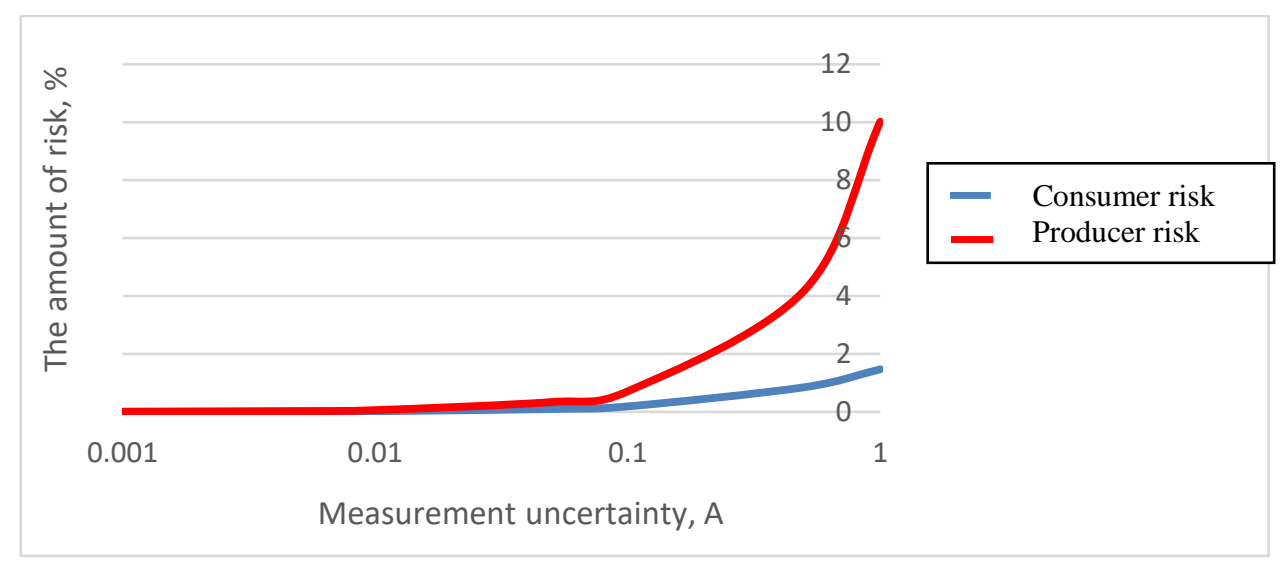

b)

Fig. 4. The impact of measurement uncertainty on consumer and producer risks

In our example, measurement uncertainty has a significant impact on the producer risk. Consumer risk is much less sensitive to the impact of measurement uncertainty. If the instrument had a measurement uncertainty of 0.1 amps, the measurement uncertainty, in terms of risk assessment, would be negligible. The proper selection of the instrument and the proper evaluation of measurement uncertainty are of great importance in conformity assessment. It is expected that the evaluated measurement uncertainty is realistic. The needs and wishes of the consumer have to be balanced against the capabilities and promises of the producer (supplier) [7]. The aim of risk analyses is to compare the parameters of a real/designed product with specification limits. Those parameters which do not meet these criteria, that is to say, parameters which transcend specification limits, must be rearranged [8]. 


\section{Conclusion}

Making a reliable decision in conformity assessment is possible after calculating conformance probability, consumer risk, producer risk and the acceptance intervals. The use of the security area provides a way to limit the probability of making wrong decisions. When defining the rules for the acceptance or rejection of an item, it is necessary to describe and document the way in which the measurement uncertainty is taken into account with respect to the measurement result and specified requirements. It's obvious that conformity assessment would be much easier if the measurement system was accurate and precise i.e. with small measurement uncertainty. In that case, risks caused by the measurement system would be negligible. Under ideal conditions, in which the measurement system would be free of measurement uncertainty and control could be carried out, the risks to the consumer and the manufacturer would be negligible. The implementation of measurement uncertainty principles as well as reliable decision making on the issue of the complementarity of results, are of great importance for conformity assessment. The example described in the paper demonstrates that calculation of conformance probability, consumer and producer risks, and acceptance intervals. In order to be carried out, this procedure requires a good understanding of probability and statistics and the application of numerical integration. Future research will include developing examples of conformity assessment and reliable decision making, which includes knowledge of measurement uncertainties, in many industry areas. The examples will allow end users to more easily manage the risks in conformity assessment.

\section{References}

[1] Publishable Summary for 17SIP05 CASoft Software to maximize end user uptake of conformity assessment with measurement uncertainty, (2018-2020)

[2] Forbes, A. B; (2006). Measurement uncertainty and optimized conformance assessment. Measurement Vol 39, 2006, pp. 808-814.

[3] JCGM 106:2012 Evaluation of measurement data - The role of measurement uncertainty in conformity assessment

[4] ASME B89.7.3.1-2001 Guidelines For Decision Rules: Considering Measurement Uncertainty In Determining Confirmation To Specification

[5] Runje, B.; Horvatić Novak, A.; Keran Z. (2018). Impact of the quality of measurement results on conformity assessment, Proceedings of the 29th DAAAM International Symposium, pp.0051-0055, Katalinic (Ed.), Published by DAAAM International, ISBN 978-3-902734-20-4, ISSN 1726-9679, Vienna, Austria DOI: 10.2507/29th.daaam.proceedings.007

[6] ISO 14253-1:1998 Geometrical Product Specifications GPS - Inspection by measurement of workpieces and measuring equipment - Part 1: Decision rules for proving conformance or non-conformance with specifications. Geneva, 1998.

[7] Pendrill, L. R.; (2014). Using measurement uncertainty in decision-making and conformity assessment, Metrologia Vol 51, No 4, 2014, pp. 206-218

[8] Broum, T.; Dvorak, J. \& Kleinova, J. (2011). Value optimization and risks elimination of product, Proceedings of the 22nd DAAAM International Symposium, pp.757-758, Katalinic (Ed.), Published by DAAAM International, ISBN 978-3-901509-83-4, ISSN 1726-9679, Vienna, Austria 